\title{
Risk Priority Number: A Measuring Instrument for Hygienic Management on Broiler Farms, Reflecting Their Campylobacter Status
}

\author{
Monika Matt ${ }^{1, *}$, Hans Peter Stüger ${ }^{2}$ and Peter Pless ${ }^{3}$ \\ 1 Department for Data, Statistics, Risk Assessment, Austrian Agency for Health and Food Safety, \\ Technikerstr. 70, Innsbruck 6020, Austria \\ 2 Department for Data, Statistics, Risk Assessment, Austrian Agency for Health and Food Safety, \\ Beethovenstr.6, Graz 8010, Austria; E-Mail: hans-peter.stueger@ages.at \\ 3 Veterinary Administration, Styrian Government, Friedrichgasse 9, Graz 8010, Austria; \\ E-Mail: peter.pless@stmk.gv.at
}

* Author to whom correspondence should be addressed; E-Mail: monika.matt@ages.at; Tel.: +43-50555-71181; Fax: +43-50555-61409.

Received: 28 June 2013; in revised form: 2 September 2013 / Accepted: 8 September 2013 / Published: 17 October 2013

\begin{abstract}
Hygiene management is essential for rearing Campylobacter free broiler flocks. In this study, several hygiene factors (e.g., thinning, water supply, stable cloths, stable condition, stable environment, etc.) are categorized and aggregated in a developed risk priority number (RPN). This number is measuring the quality of hygiene management of a broiler farm with one single value (range: $801-4005$ points), the higher the RPN, the better is the hygiene status. The distribution of the values is left skewed and none of the 53 examined Austrian broiler farms reached the maximum. Cecal samples $(n=610)$ from broilers at the point of slaughter determined the Campylobacter status of the farms. Farms with a high RPN consistently produced more Campylobacter free batches than farms with a low RPN. Ranking of the broiler farms based on their RPN was significantly correlated with their microbiological results for Campylobacter detection (Spearman's correlation coefficient $=0.646$ ). The risk priority number is an easy tool for the assessment and measurement of the hygiene management system at a broiler farm. Besides the educational benefits of the RPN, benchmarking against the mean value or the maximum is possible.
\end{abstract}

Keywords: Campylobacter; control options; hygiene management; broiler farms 


\section{Introduction}

Campylobacter is recognized as the most common bacteria to cause foodborne, diarrheal illness in Europe with 220,209 confirmed cases in 2011 [1], including 43 deaths. In Austria 4855 cases have been notified in 2012 [2], including one fatality. Clinical symptoms of campylobacteriosis include diarrhea, abdominal cramps and fever that may last for a few days (typically three to six). Beside these symptoms sequelae like Guillain-Barré syndrome or reactive arthritis are well described $[3,4]$.

The major source of infection is poultry meat [5,6], as indicated by the Dioxin crisis in Belgium, where the incidence of campylobacteriosis dropped in the same amount as the consumption of chicken was reduced [7]. The adverse effect was shown in Iceland, where the human disease increased strongly with the availability of fresh poultry meat. Due to several strategies concerning poultry meat, the amount of ill people could be controlled again [8]. Other approaches like source attribution and genetic research endorse poultry as the most likely source of infection [9-11].

Campylobacter may colonize the gut of birds and multiply symptomless. Vertical infection of broilers is negligible as Campylobacter can rarely be detected in hatched chickens [12,13]. Therefore the Campylobacter infection occurs via several transmission routes from exterior. Biosecurity is targeted at Campylobacter-entry and is accepted as an important intervention at primary production [14].

Once a bird of the flock is colonized, Campylobacter spreads within the flock in less than one week [15] and concentrations may reach $9.8 \mathrm{log}$ CFU/g of feces [16]. Subsequently, contamination of feces during the transport and slaughter process results in Campylobacter positive carcasses.

Risk factors and control options at the farm level have been described in several reports [14,17-22] and focus on a bacterial load reduction in feces or the disruption of possible transmission routes. Reduction of Campylobacter load in feces includes vaccination of broilers, phage therapy and food additives but these treatments are not commercially available yet. For this reason, hygiene management seems the only possible way for prevalence reduction at the moment [21].

Hygiene management or biosecurity is not strictly defined and includes a number of measures related to the pathogen. As the infective dose for Campylobacter is very low, a single inadvertence may immediately result in a positive flock as they spread rapidly [23]. One single effective intervention measure like vaccination does not exist, creating significant insecurity for farmers as they do not know exactly how to avoid Campylobacter positivity. Additionally, the effectiveness of some specific hygiene interventions is doubted or has to be further evaluated, e.g., fly screens [24].

Due to this background, we searched for an easy tool to deal with this complex situation. The risk priority number (RPN) which is used in failure mode and effects analysis (FMEA) [25] served as a basis for further work. FMEA is an established tool in several fields, such as e.g., automotive industry, quality management systems [26]. We developed a modified RPN concerning Campylobacter by summing up common hygiene factors, previously classified in five gradations. This single value expresses the hygiene management of a given farm regarding the Campylobacter thread.

Risk factor surveys usually relate the Campylobacter status of a single flock to a questionnaire. It should be recognized from the outset that our approach differs somewhat from earlier studies. We used expert knowledge of the regional poultry health service and experience from official vets for a classification scheme which we interrelated with the Campylobacter farm status over several fattening trials. Depending on the microbiological results after first and subsequent depopulations the farm 
status was assessed. An additional aspect in this work is that an official veterinary visited the farms and conducted a rating based on 18 hygiene factors. This rating is very different to questionnaires, as it is independent of the farmer's own perception of his/her attitude.

We wanted to test, if the constructed RPN correlates well with the Campylobacter-status of the farm. A single number representing the whole complex "hygiene status" of a specific farm could serve as a tool for farmers and vets to illustrate room for improvement. This could help to increase biosecurity in Austrian broiler farms and, therefore, decrease the number of Campylobacter positive flocks. As this directly and indirectly affects the incidence of human campylobacteriosis, an increase of biosecurity in all Austrian broiler farms might be protective for birds and humans.

\section{Results and Discussion}

In summer and autumn 2010, Austrian broiler farms $(n=53)$ were visited by official veterinarians who assessed the hygiene status with a given scheme. This period was chosen as a higher percentage of Campylobacter positive flocks are expected and therefore the explanatory power of the RPN can be investigated straightforwardly, though a survey over a one-year period would give a broader data set and the possibility to search for possible seasonal effects. The scheme consists of 18 hygiene factors, including cleaning and disinfection of the stable, collection system, thinning frequency, other animals or pets on the farm, litter materials, hygiene sluice, pest security, litter storage, number of stables, water supply, manure storage, stable environment, stable condition, ventilation system, chicken watering equipment, feeding, stable cloth, and hygiene equipment for personal use. These variables were graded from $1-5$ ( 5 is the best) as illustrated in Table 1.

Table 1. Description of hygiene factor classification and weighting.

\begin{tabular}{|c|c|c|}
\hline Hygiene factor & Classification (1-5) & Weight \\
\hline \multirow{5}{*}{ collection system } & $5=$ harvester crew without contact to other poultry farms & \multirow{5}{*}{100} \\
\hline & $4=$ harvester crew exclusively visits one farm per day & \\
\hline & $3=$ harvester crew visits $>1$ farm per day & \\
\hline & $2=$ harvester crew visits $>1$ farm per day, use of chicken catching machine & \\
\hline & $\begin{array}{l}1=\text { harvester crew two or more plants per day, no change of cloth, no } \\
\text { correct cleaning and disinfection of the crew }\end{array}$ & \\
\hline \multirow{3}{*}{$\begin{array}{l}\text { thinning } \\
\text { frequency }\end{array}$} & $5=$ no partial slaughter & \multirow{3}{*}{100} \\
\hline & $3=2$ days of partial depopulation & \\
\hline & $1=\geq 3$ days of collection & \\
\hline \multirow{5}{*}{$\begin{array}{l}\text { other animals or } \\
\text { pets on/nearby } \\
\text { the farm }\end{array}$} & $5=$ no other animals (poultry) and pets on and nearby the farm & \multirow{5}{*}{100} \\
\hline & $4=$ no other animals within $100 \mathrm{~m}$ & \\
\hline & $3=$ farmer keeps pets, no livestock & \\
\hline & $2=$ livestock at the farm, pets; & \\
\hline & $1=$ livestock in the same stable (building), more pets & \\
\hline \multirow{5}{*}{ water supply } & $5=$ mains water & \multirow{5}{*}{10} \\
\hline & $4=$ own spring water & \\
\hline & $3=$ ground water & \\
\hline & $2=$ own spring water, contaminated with $\boldsymbol{E}$. coli/Enterococci & \\
\hline & $1=$ ground water, contaminated with $\boldsymbol{E}$. coli/Enterococci & \\
\hline
\end{tabular}


Table 1. Cont.

\begin{tabular}{|c|c|c|}
\hline Hygiene factor & Classification (1-5) & Weight \\
\hline \multirow{5}{*}{ pest security } & $\begin{array}{l}5=\text { stable, incl. hygiene slice and anteroom, stable environment protected, } \\
\text { fly control }\end{array}$ & \multirow{5}{*}{100} \\
\hline & 4 = stable protected; & \\
\hline & $3=$ grids in need of repair; & \\
\hline & 2 = inadequate & \\
\hline & $1=$ bad condition & \\
\hline \multirow{5}{*}{$\begin{array}{l}\text { number of } \\
\text { stables }\end{array}$} & $5=$ only 1 stable at the farm; & \multirow{5}{*}{10} \\
\hline & $4=2$ stables, separated, distance $\geq 10 \mathrm{~m}$, & \\
\hline & $3=2$ units in one stable & \\
\hline & $2=$ more than 2 units in one stable & \\
\hline & $1=2$ or more stables at the farm, 2 or more units in the stable & \\
\hline \multirow{5}{*}{$\begin{array}{l}\text { stable } \\
\text { environment }\end{array}$} & $5=$ completely fortified & \multirow{5}{*}{10} \\
\hline & $4=$ about $30 \%$ fortified, $70 \%$ gravel, gras & \\
\hline & $3=$ about $30 \%$ fortified, $70 \%$ field, gravel, gras & \\
\hline & $2=$ marginally fortified, bushes and plant growth & \\
\hline & $1=$ marginally fortified, plant growth, storage of materials and waste & \\
\hline \multirow{5}{*}{$\begin{array}{l}\text { structural/ } \\
\text { technical stable } \\
\text { condition }\end{array}$} & $5=$ new stable (younger than 10 years), good condition & \multirow{5}{*}{10} \\
\hline & $4=\geq 10$ years, renovated, good condition & \\
\hline & $3=$ new stable, moderate condition & \\
\hline & $2=$ new stable, bad condition & \\
\hline & $1=$ old stable, bad condition & \\
\hline \multirow{5}{*}{$\begin{array}{l}\text { ventilation } \\
\text { system }\end{array}$} & $5=$ side wall — ceiling ventilation, high outlet & \multirow{5}{*}{10} \\
\hline & $4=$ side wall — ceiling ventilation, low outlet & \\
\hline & $3=$ side wall in/out ventilation, clean outside & \\
\hline & $2=$ side wall in/out ventilation, bushes outside & \\
\hline & $1=$ side wall in/out ventilation, bushes, storage of materials and waste outside & \\
\hline \multirow{5}{*}{$\begin{array}{l}\text { chicken watering } \\
\text { equipment }\end{array}$} & $5=$ nipple drinker with tray, bedding material dry & \multirow{5}{*}{10} \\
\hline & $4=$ nipple drinker with tray, bedding material nearly dry & \\
\hline & $3=$ nipple drinker with tray/round drinker, bedding material moist & \\
\hline & $2=$ nipple drinker with tray/round drinker, bedding material wet & \\
\hline & $1=$ round drinker, bedding material wet, litter flour plates & \\
\hline \multirow{5}{*}{ feeding } & $5=$ closed supply system, feed delivery, protected area & \multirow{5}{*}{10} \\
\hline & 4 = closed supply system, feed delivery, no protected area & \\
\hline & $3=$ Silo, covered feed self-transport & \\
\hline & $2=$ open feed container, covered feed self-transport & \\
\hline & $1=$ open feed container, feed self-transport & \\
\hline \multirow{5}{*}{$\begin{array}{l}\text { hygiene sluice, } \\
\text { barrier, changing } \\
\text { room }\end{array}$} & $\begin{array}{l}5 \text { = hygiene sluice present, changing room clean, hygiene barrier outside } \\
\text { of farm }\end{array}$ & \multirow{5}{*}{100} \\
\hline & 4 = changing room clean, proper disinfectant mat, no hygiene sluice & \\
\hline & $3=$ changing room untidy, proper disinfectant mat, no hygiene barrier & \\
\hline & $2=$ improper changing room, improper disinfectant mat & \\
\hline & $1=$ no anteroom existent, no disinfectant mat existent & \\
\hline
\end{tabular}


Table 1. Cont.

\begin{tabular}{|c|c|c|}
\hline Hygiene factor & Classification (1-5) & Weight \\
\hline \multirow{5}{*}{ litter materials } & $5=$ dry corn cob, soft cells or straw pellets & \multirow{5}{*}{100} \\
\hline & $4=$ straw or food shavings, dry & \\
\hline & $3=$ straw or food shavings, slightly moist & \\
\hline & $3=$ straw or food shavings, moist & \\
\hline & $1=$ straw or food shavings moist and constantly crusted & \\
\hline \multirow{5}{*}{$\begin{array}{l}\text { cleaning and } \\
\text { disinfection of } \\
\text { the stable }\end{array}$} & $\begin{array}{l}5 \text { = complete manure removal, dry cleaning, hot water cleaning, spray } \\
\text { disinfection in no wet area, pat dry }\end{array}$ & \multirow{5}{*}{100} \\
\hline & 4 = dry cleaning, cold water cleaning, disinfection, dampish-dry & \\
\hline & $3=$ dry cleaning elusive, cold water cleaning, disinfection, dampish-dry & \\
\hline & $2=$ dry cleaning elusive, cold water cleaning, disinfection only in wet area & \\
\hline & $1=$ no correct litter removal, dry cleaning, disinfection only in wet area & \\
\hline \multirow{5}{*}{ stable cloth } & $5=$ own clothes and footwear for farmer and visitor, correct change & \multirow{5}{*}{10} \\
\hline & $4=$ own clothes and footwear for farmer (not for visitor), correct change & \\
\hline & $3=$ own clothes and footwear for farmer, insufficiently change & \\
\hline & $2=$ own stable cloths dirty, footwear dirty, & \\
\hline & $1=$ no stable clothes and footwear, no change & \\
\hline \multirow{5}{*}{$\begin{array}{l}\text { hygiene } \\
\text { equipment for } \\
\text { personal }\end{array}$} & $5=$ shower, sink properly functioning \& clean, detergents and disinfectants ok & \multirow{5}{*}{1} \\
\hline & $4=$ sink properly functioning $\&$ clean, detergents and disinfectants ok & \\
\hline & $3=$ sink properly functioning but dirty, no detergents and disinfectants & \\
\hline & $2=$ only cold water, dirty, detergents and disinfectants & \\
\hline & $1=$ no shower, sink, no detergents and disinfectants & \\
\hline \multirow{5}{*}{ litter storage } & $5=$ closed, protected, clean & \multirow{5}{*}{10} \\
\hline & $4=$ closed, protected, little bit dirty & \\
\hline & $3=$ closed, not protected, dirty & \\
\hline & $2=$ roofed, accessible for rodents, birds & \\
\hline & $1=$ largely unprotected area, other equipment materials and waste closely & \\
\hline \multirow{5}{*}{ manure storage } & $5=$ distance $\geq 1 \mathrm{~km}$, fortified & \multirow{5}{*}{10} \\
\hline & $4=500 \mathrm{~m}-1000 \mathrm{~m}$ & \\
\hline & $3=100 \mathrm{~m}-500 \mathrm{~m}$ & \\
\hline & $2=20 \mathrm{~m}-100 \mathrm{~m}$ & \\
\hline & $1=$ directly beside the stable & \\
\hline
\end{tabular}

Besides scoring the management system, cecal samples have been tested for Campylobacter in each slaughtered batch. In total, 610 samples have been investigated, 421 were Campylobacter positive. Figure 1 shows the detailed results including the confidence interval bars. The overall prevalence was $69 \%$. As the project period was during summer and autumn, this prevalence is in agreement with the results from 2008 [27], where the prevalence was higher in May-September than in October-November. 
Figure 1. Campylobacter positive batches at slaughter.

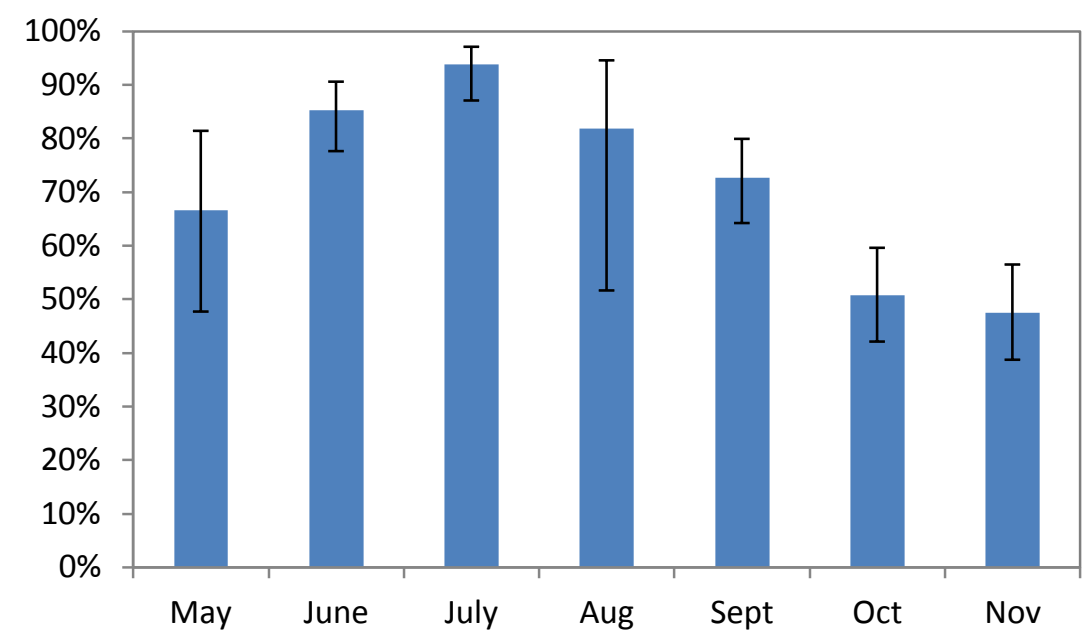

The Campylobacter results of each farm have been classified concerning the consistency of the cecal results. The values were scaled into always positive (value $=1$ ), always negative (value $=5$ ) and in between (values $=2,3$ or 4). Table 2 in the experimental section shows the exact procedure as well as the number of the farms per cecal category. Only 4 (7.5\%; CI 4-20) farms remained free from Campylobacter during the investigation period. This reflects the pressure of environmental sources for infection in summer, where temperature, sunshine and humidity influence the prevalence of Campylobacter [28].

Table 2. Description of cecal categories for Campylobacter.

\begin{tabular}{|c|c|c|}
\hline Cecal category & Campylobacter results & $\begin{array}{c}\text { Number of farms in } \\
\text { this category }(\%)\end{array}$ \\
\hline 1 & all broiler flocks positive: all batches of each flock positive & $15(28.3 \%$, CI $18-42)$ \\
\hline 2 & $\begin{array}{l}\leq 50 \% \text { of the first depopulation are negative } \\
-\quad \text { all subsequent batches positive } \\
\leq 50 \% \text { of the first depopulation are negative }\end{array}$ & $12(22.6 \%$, CI $13-36)$ \\
\hline 3 & $\begin{array}{l}\text { - no thinning is practiced, } \\
\text { - if thinning practiced: some subsequent batches positive }\end{array}$ & $12(22.6 \%$, CI $13-36)$ \\
\hline 4 & $>50 \%$ of the first depopulation are negative; & $10(18.9 \%$, CI $11-31)$ \\
\hline 5 & all broiler flocks negative: all batches of each flock negative & $4(7.5 \%$, CI $3-18)$ \\
\hline
\end{tabular}

\subsection{Hygiene Factors}

The observed percentage within each variable is visualized in Figure 2. Each hygiene factor is graduated into 5 categories. The class with lowest hygiene level is rated with 1 ; the highest hygiene class is rated with 5. The exact classification is described in Table 1. In a previous work, which was done after the construction of the RPN by the expert team, the odds ratio for each hygiene factor has been calculated [29]. Description and discussion of four categories with the highest significant odds is given in this section: collection system, pest security, stable environment and thinning frequency. 
Figure 2. Observed category (described in Table 1) within each hygiene factor.

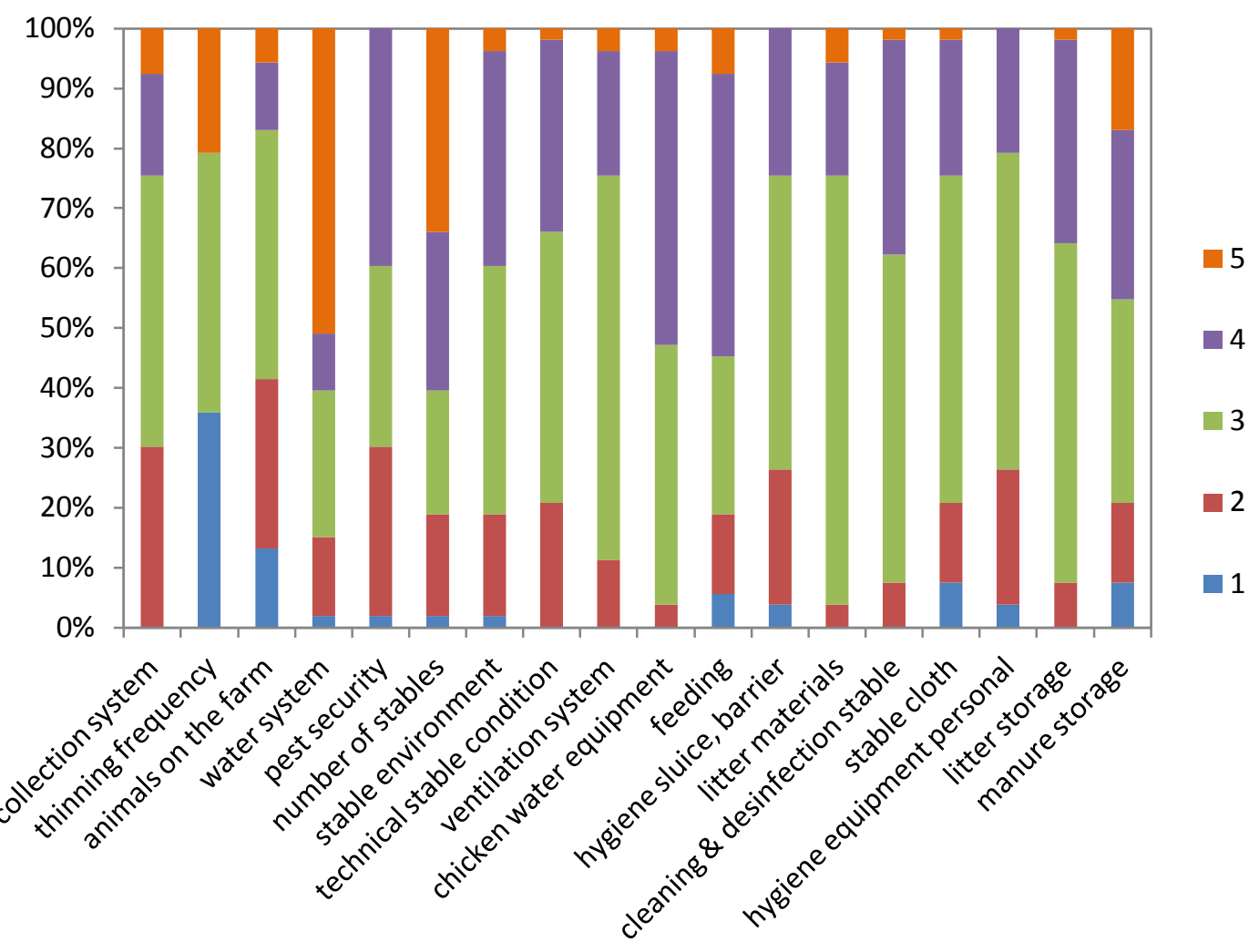

The collection system varies within farms with thinning. The majority of the harvester crews visit more than one farm per day (sum of category 2 and $3=75.5 \%$ ), all the rest (category 4 and 5) exclusively visit one farm per day. Some crews (category $5=7.5 \%$ ) do not even have contact to other poultry farms. No harvester crew totally ignores any hygienic management guidelines (category 1).

Rodents and insects may lead to Campylobacter colonization of broiler flocks [30,31] and therefore is identified as an important factor [32]. Though pest control is mandatory in Austria for broiler flocks [33], the quality of pest control was in bad condition or inadequate in $30 \%$ of the visited farms. In another $30 \%$, broken grids were identified which need to be mended. The stables are protected against rodents in $40 \%$, but no farm had protected anterooms or fly screens. Fly screens at farms with high hygiene standard had been identified to reduce the amount of Campylobacter positive flocks [34].

At the majority (78\%) of the investigated farms about a third of the stable environment was fortified and therefore dedicated to category 3 and 4. Completely fortified stable environments were observed in two farms only. Plant growth, bushes and marginally fortified surroundings were seen on the other farms (19\%), and in two locations waste and material were stored next to the broiler house.

Partial depopulation or thinning is a risk factor for Campylobacter colonization of flocks [12,35]. Thinning is common practice as $4 / 5$ of the visited farms deliver more than one batch to the slaughterhouse, $1 / 5$ practices "all in all out". On $36 \%$ of the farms thinning takes place more than two times. Partial depopulation is an economic way to fulfill the animal protection act, as stocking density in Austria is $30 \mathrm{~kg} / \mathrm{m}^{2}$. Additionally, retail requires birds of different weights for different products, and higher productivity is ensured. Due to these facts, a ban of thinning is unrealistic. Alternatively strict hygiene requirements for personal and equipment are essential and contaminated crates pose an 
inevitable risk [36]. Extended storage without thorough cleaning and disinfection does not reduce the number of Campylobacter efficiently enough [37], and, furthermore, superficial cleaning of crates may infect the remaining flock [38].

\subsection{Risk Priority Number}

The risk priority number delineated in this manuscript is the sum of 18 weighted hygiene factors described in Table 1. The weighting scheme (factor 100 for the most important hygiene factors followed by 10 and 1) was conducted by an expert team to gradate and emphasize specific factors.

Some mathematical variants have been tested and compared with each other, as described in the experimental section 3.3. In general, there is a very good correlation between the designed RPN's: The Spearman rank correlation between RPN and $\mathrm{RPN}_{\text {red }}$ is 0.994 , between RPN and $\mathrm{RPN}_{\text {unwtd }}$ is 0.893 . Despite this correlation, we decided to describe the results using the initial RPN construction, for the sake of generalization and as description of a general concept. Omitting 10 hygiene factors $\left(\mathrm{RPN}_{\mathrm{red}}\right)$ contradicts with previous findings, using another analysis tool: the odds ratio of a binary categorized hygiene factor data set [29]. The odds ratio for stable environment, indicated as risk factor [18] and excluded in $\mathrm{RPN}_{\text {red, }}$, is the same as for pest security which is included in RPN. Furthermore, these variables are still indicative, as they have been identified in several studies as risk factors, such as water supply [12,22] or the number of stables [17,22].

On top of this, the weighted RPN correlated best with the cecal category. The correlation between each variant of the RPN and the cecal category was calculated using Spearman's rank correlation coefficient test, which gave a significant results (significance level 0.01) for all variants: the unweighted RPN ( $\left.\rho_{\text {unwtd }}=0.551\right)$, the reduced RPN ( $\left.\rho_{\text {red }}=0.645\right)$ and the weighted RPN $(\rho=0.646)$.

According to the small industry structure in Austria, the distribution within one category differs to other countries [27]. A lack of correlation between the RPNs might be observed in such data set. Furthermore the additional value and effectiveness of weighting has been demonstrated [39], therefore it is feasible to keep all variables and weights in the first calculation.

In summary the benefit of using a mixture of different management issues, concerning 18 weighted hygiene factors, overcomes ambiguity. As the RPN serves as an educative tool which should lead to intensive discussion between vets and farmers, weighting and the usage of all factors seems beneficial for initial usage of this concept. Notwithstanding, the RPN-variant which performs best in the field has to be evaluated further in future.

\subsubsection{Descriptive Statistics of the RPN}

The possible range of RPN's is 801-4005, but no farm reached the best score of 4005 . The lowest observed RPN was 1772 points, the average 2441 with a standard deviation of 341 . The 25 th percentile was 2172 points, the median 2393 points and the 75 th percentile was 2683 points. The highest observed RPN was 3114 points.

A high RPN reflects allover excellent hygiene management, whereas a low number indicates potential of improvement on farm and management system. In Figure 3, a histogram of the RPN values demonstrates a left skewed distribution. 
Figure 3. Histogram of risk priority number (RPN) values.

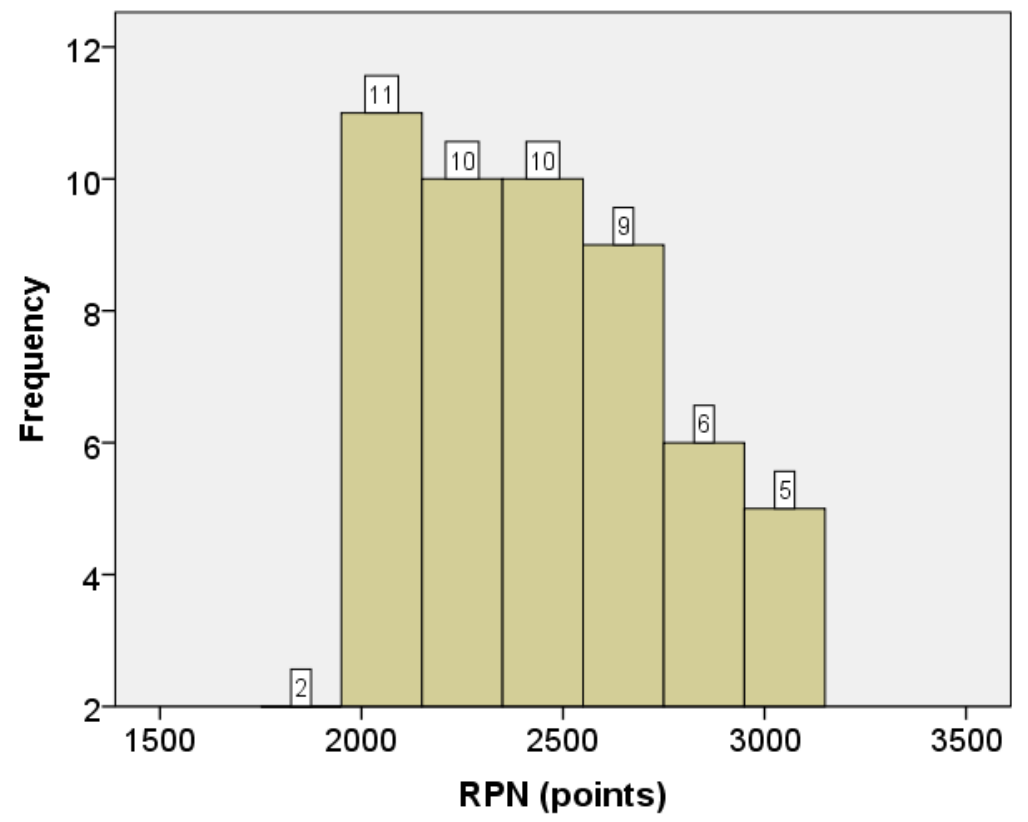

\subsubsection{Correlation of RPN and Campylobacter Status}

As the RPN is the sum of 18 values from different hygiene factors, its magnitude reflects the accumulated hygiene management status of each farm. Low numbers indicate poor hygiene management regarding to Campylobacter protection of the broilers. In Figure 4, the RPN-cecal category pairs are plotted for a first visualization of the results. For example, the farm with 1772 points produced all-positive flocks and at the farm with 1823 points, $\leq 50 \%$ of the first depopulated batches were the only negative batches. All farms with a number $>3000$ points can be found in cecal category 4 and 5 which reflects principally absence of Campylobacter.

Figure 4. Scatter plot with all RPN-cecal category-pairs: visualization of the correlation between RPN and Campylobacter status of flocks.

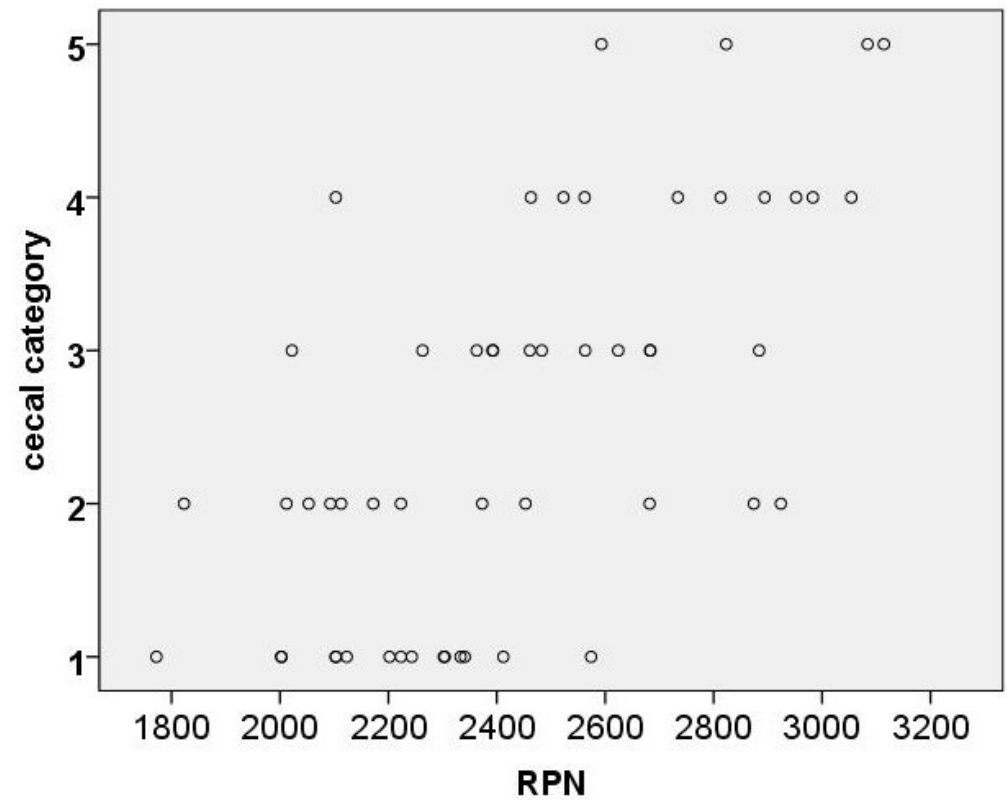


Another integrated illustration is by way of the tendency of the mean Campylobacter: positive farms have a low RPN mean whereas Campylobacter negative farms have high values concerning the cecal categories, which is shown in Figure 5. Statistics were used to determine this connectedness. The different cecal categories were tested for the differences of the means (RPN) with one-way ANOVA, leading to the conclusion that the means are significantly different $(p<0.0001)$. A non-parametric approach with the Kruskal-Wallis-Test gave the same results.

Figure 5. Means of RPN in relation to the Campylobacter category.

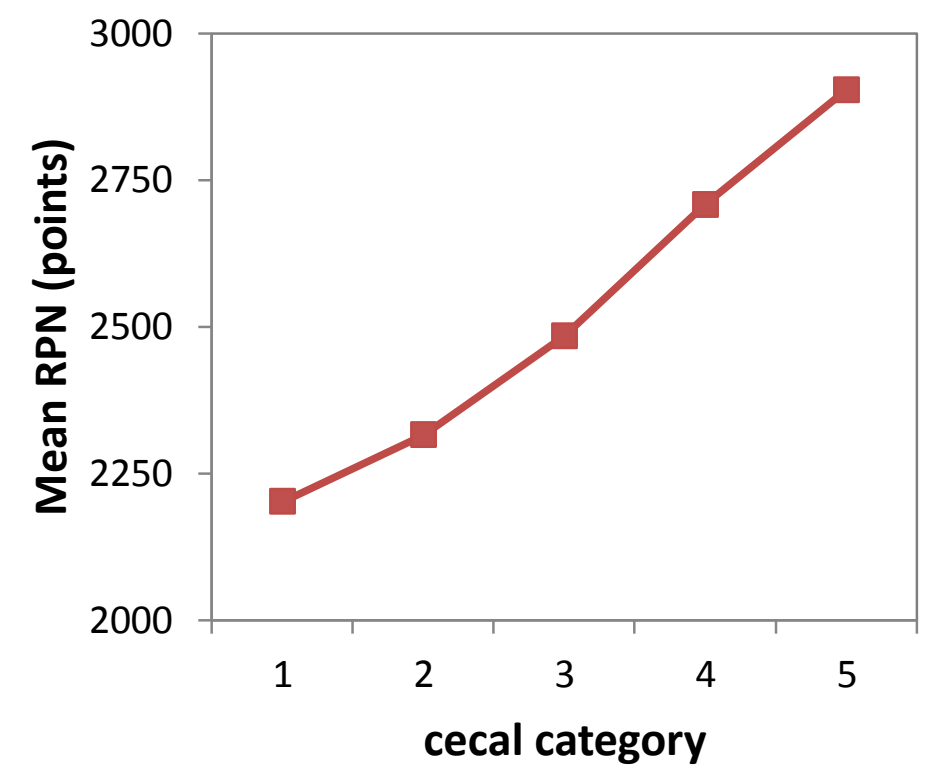

Furthermore the correlation between the farms ranking based on the RPN and the ranking based on the cecal Campylobacter status of the farms was evaluated using Spearman's rank correlation coefficient test, which gave a significant result $(\rho=0.646$, significance level 0.01$)$.

In general, hygiene management is described in a qualitative way including various aspects. Therefore, it is quite hard to give a straightforward answer concerning the performance of a specific operator. Hygiene management in slaughterhouses faces the same problem and Habib et al. [40] tried to overcome this problem using the FASFC check scores from the Belgium official control inspection correlating them with the Campylobacter prevalence on the broiler carcasses.

A collective indicator for poor resp. good hygiene management at a broiler farm is not in place in Austria; therefore, constructing the RPN is a first move. This single value gives a strong indication for the hygiene quality of a specific farm. Furthermore, an increase of the RPN may influence the probability of Campylobacter negative flocks. Low scores within a category should be avoided and a higher score is a reachable aim. Another aspect is the usage as a benchmark: a farmer can compare the own classification with the best (3114 points in this study) or the mean (2441 points). As a consequence, the RPN may be used to set a status quo, as a motivation tool or simply as a starting point for discussion between the farmer and others (veterinarians, poultry health services). 


\section{Experimental Section}

\subsection{Campylobacter Status of the Flocks}

\subsubsection{Microbiological Methods}

The Campylobacter status of 53 Austrian farms was investigated from May to November 2010. Therefore 610 pooled cecal samples of 5 broilers per batch were tested for the presence of Campylobacter jejuni/coli. A batch is defined as a group of broilers slaughtered from one flock at the same time. Thinning is quite common in Austria ( $80 \%$ of the farms); therefore, fecal droppings at farm level could not be utilized as a matrix for Campylobacter examination, as the association between the sample and the slaughter batch cannot be guaranteed. Cloacal swabs could serve as another matrix for Campylobacter detection. The sampling for cloacal swabs is much more laborious than the collection of ceca at the slaughterhouse. Moreover, the sensitivity of testing cecal content is higher than cloacal swabs [41].

The detection method for pooled cecal samples was according to ISO 10272 [42] with slight modifications: omitting the pre-enrichment step with Bolton broth and performing direct plating on modified Charcoal-Cefoperazone-Deoxycholate Agar (mCCDA).

\subsubsection{Classification of the Campylobacter Results}

A Campylobacter investigation was conducted in each slaughtered batch. In accordance to the hygiene variables, the highest score reflects the optimal situation: the higher the score the better the results. A description of the cecal categories and the numbers of farms within each group are given in Table 2.

To determine a status for a farm and not a single flock results for different flocks and thinned batches have been considered. If all flocks and batches were positive or negative the farms were categorized in category 1 respectively in category 5,. Farms with a negative result in more than 50\% of the first batches were subsumed in category 4 . If the results of the first batches were negative in $50 \%$ or less, the results of the subsequent batches determined the category: solely positive results reflected category 2, whereas the absence of subsequent batches (no thinning practiced) or some positive results mixed with some negative results represented category 3 .

\subsection{Hygiene Factors}

Several beneficial and impending hygiene criteria concerning Campylobacter colonization of broiler are described in literature [12,18,22,30]. An expert team for broiler production (members of the Austrian Poultry Health Service, veterinary specialists for poultry and official vets) compiled a catalogue of hygiene criteria for broiler farms. They considered the most important factors for regional broiler farms and developed a scoring scheme depending on their impact on Campylobacter colonization (Table 1). With regard to Xiao et al. [39] who have extended the definition of RPN with weighted parameters, the relative importance of distinct criteria was expressed by weighting with 1, 10 and 100 [43]. 


\subsection{Risk Priority Number}

The construction of the risk priority number (as well as the cecal category) is based on the slogan: the more the better. In this case, a high number represents a high hygiene quality on a farm. The hygiene criteria and weighting scheme from the expert team (Table 1) builds the basis.

The RPN used in this manuscript is reflected by the sum of weighted hygiene factors per farm. The Spearman rank correlation coefficient is used to evaluate different compositions: addition of weighted categories (RPN), addition of unweighted categories ( $\mathrm{RPN}_{\text {unwtd }}$ ), omitting 10 variables with weights $<100\left(\mathrm{RPN}_{\mathrm{red}}\right)$. As the RPN with the weighted categories shows the highest correlation with the cecal category, this variant was chosen in this manuscript.

\subsection{Statistics}

Confidence intervals for percentages were calculated with a Bayesian approach using a Beta(1,1)-prior function. Differences between means resp. medians were tested with oneway-ANOVA and the non-parametric Kruskal-Wallis-Test Correlation was determined with Spearman ranks correlation coefficients, SPSS 19 was used for all calculations.

\section{Conclusions}

In general, a high biosecurity standard is recommended for the prevention of Campylobacter entering a broiler flock. Additionally, some other factors may increase the chance of producing Campylobacter free broiler batches (e.g., no other animals nearby). The results emphasize the crucial interaction between different factors and the hygiene compliance to rear Campylobacter-free flocks.

The RPN measures the quality of the current hygiene management at a specific farm within one single, simple number in relation to its Campylobacter status. All farms with exclusive Campylobacter free batches have higher RPN scores than other farms, and we think that farms with a high RPN consistently produce more Campylobacter free batches than farms with a low RPN. This may be used as an educative tool, motivation tool and as a benchmark.

Consequently, these results form the basis for a predictive tool which is under development now. Such a tool will predict the Campylobacter status with as little uncertainty as possible and therefore will help - at least in an educational sense - to combat Campylobacter colonization of broilers and, hence, reduce the risk of campylobacteriosis of humans.

\section{Conflicts of Interest}

The authors declare no conflict of interest.

\section{References}

1. European Food Safety Authority (EFSA). ECDC The European Union summary report on trends and sources of zoonoses, zoonotic agents and food-borne outbreaks in 2011. EFSA J. 2013, 11, 3129; doi:10.2903/j.efsa.2013.3129. 
2. Jelovcan, S.; Kornschober, C. Jahresbericht Campylobacter 2012; Austrian Agency for Health and Food Safety: Graz, Austria, 2013.

3. Yu, R.K.; Usuki, S.; Ariga, T. Ganglioside molecular mimicry and its pathological roles in Guillain-Barre syndrome and related diseases. Infect. Immun. 2006, 74, 6517-6527.

4. Hannu, T. Campylobacter-triggered reactive arthritis: A population-based study. Rheumatology 2002, 41, 312-318.

5. EFSA Panel on Biological Hazards (BIOHAZ). Scientific Opinion on Quantification of the risk posed by broiler meat to human campylobacteriosis in the EU. EFSA J. 2010, 8, doi:10.2903/ j.efsa.2010.1437.

6. Scientific Committee of the Food Safety Authority of Ireland (FSAI). Recommendations for a Practical Control Programme for Campylobacter in the Poultry Production and Slaughter Chain; Food Safety Authority of Ireland: Dublin, Ireland, 2011.

7. Vellinga, A. The dioxin crisis as experiment to determine poultry-related campylobacter enteritis. Emerg. Infect. Dis. 2002, 8, 19-22.

8. Stern, N.J.; Hiett, K.L.; Alfredsson, G.A.; Kristinsson, K.G.; Reiersen, J.; Hardardottir, H.; Briem, H.; Gunnarsson, E.; Georgsson, F.; Lowman, R.; et al. Campylobacter spp. in Icelandic poultry operations and human disease. Epidemiol. Infect. 2003, 130, 23-32.

9. Mullner, P.; Jones, G.; Noble, A.; Spencer, S.E.F.; Hathaway, S.; French, N.P. Source attribution of food-borne zoonoses in New Zealand: A modified Hald model. Risk Anal. 2009, 29, 970-984.

10. Sheppard, S.K.; Jolley, K.A.; Maiden, M.C.J. A gene-by-gene approach to bacterial population genomics: Whole genome MLST of Campylobacter. Genes 2012, 3, 261-277.

11. Strachan, N.J.C.; Gormley, F.J.; Rotariu, O.; Ogden, I.D.; Miller, G.; Dunn, G.M.; Sheppard, S.K.; Dallas, J.F.; Reid, T.M.S.; Howie, H.; et al. Attribution of Campylobacter infections in northeast Scotland to specific sources by use of multilocus sequence typing. J. Infect. Dis. 2009, 199, 1205-1208.

12. Newell, D.G.; Fearnley, C. Sources of Campylobacter colonization in broiler chickens. Appl. Environ. Microbiol. 2003, 69, 4343-4351.

13. Sahin, O.; Kobalka, P.; Zhang, Q. Detection and survival of Campylobacter in chicken eggs. J. Appl. Microbiol. 2003, 95, 1070-1079.

14. EFSA. Scientific Opinion on Campylobacter in broiler meat production: Control options and performance objectives and/or targets at different stages of the food chain. EFSA J. 2011, 9, doi:10.2903/j.efsa.2011.2105.

15. Van Gerwe, T.J.W.M.; Bouma, A.; Jacobs-Reitsma, W.F.; van den Broek, J.; Klinkenberg, D.; Stegeman, J.A.; Heesterbeek, J.A.P. Quantifying transmission of Campylobacter spp. among broilers. Appl. Environ. Microbiol. 2005, 71, 5765-5770.

16. Pölzler, T.; Wagner, M.; Slaghuis, J.; Schleicher, C.; Köfer, J. Rapid monitoring of Campylobacter in high-shedding flocks for targeted disease control. J. Food Prot. 2012, 75, 1835-1838.

17. Bouwknegt, M.; van de Giessen, A.W.; Dam-Deisz, W.D.C.; Havelaar, A.H.; Nagelkerke, N.J.D.; Henken, A.M. Risk factors for the presence of Campylobacter spp. in Dutch broiler flocks. Prev. Vet. Med. 2004, 62, 35-49.

18. Hansson, I.; Engvall, E.O.; Vågsholm, I.; Nyman, A. Risk factors associated with the presence of Campylobacter-positive broiler flocks in Sweden. Prev. Vet. Med. 2010, 96, 114-121. 
19. Humphrey, T.; Paulsen, P.; Pfeifer, A.; Smulders, F.J.M. Campylobacter as the main zoonotic pathogen in poultry and strategies for its control. Vet. Med. Austria 2012, 99, 330-336.

20. Newell, D.G.; Elvers, K.T.; Dopfer, D.; Hansson, I.; Jones, P.; James, S.; Gittins, J.; Stern, N.J.; Davies, R.; Connerton, I.; et al. Biosecurity-based interventions and strategies to reduce Campylobacter spp. on poultry farms. Appl. Environ. Microbiol. 2011, 77, 8605-8614.

21. Klein, G. Interventionsmaßnahmen gegen Campylobacter in der Primärproduktion und in der Geflügelfleischgewinnung. Archiv für Lebensmittelhygiene 2010, 61, 108-111.

22. Nather, G.; Alter, T.; Martin, A.; Ellerbroek, L. Analysis of risk factors for Campylobacter species infection in broiler flocks. Poult. Sci. 2009, 88, 1299-1305.

23. Berndtson, E.; Danielsson-Tham, M.-L.; Engvall, A. Campylobacter incidence on a chicken farm and the spread of Campylobacter during the slaughter process. Int. J. Food Microbiol. 1996, 32, 35-47.

24. Amtliche Veterinärnachrichten-Nr. 06/2013 vom 19. Juli 2013, GZ. 74.200/0024-II/B/10/2013; Ministry of Health: Vienna, Austria, 2008.

25. International Standard Analysis Techniques for System Reliability-Procedure for Failure Mode and Effects Analysis (FMEA); IEC 60812:2006; International Electrotechnical Commission: Geneva, Switzerland, 2006.

26. Aldridge, J.R.; Dole, B.G. Managing Quality, 4th ed.; Dole, B.G., Ed.; Blackwell Pub.: Malden, MA, USA, 2003; pp. 389-405

27. EFSA. Scientific report of EFSA: Analysis of the baseline survey on the prevalence of Campylobacter in broiler batches and of Campylobacter and Salmonella on broiler carcasses in the EU, 2008 Part A: Campylobacter and Salmonella prevalence estimates. EFSA J. 2010, 8, 1503; doi:10.2903/j.efsa.2010.1503.

28. Jorgensen, F.; Ellis-Iversen, J.; Rushton, S.; Bull, S.A.; Harris, S.A.; Bryan, S.J.; Gonzalez, A.; Humphrey, T.J. Influence of season and geography on Campylobacter jejuni and C. coli subtypes in housed broiler flocks reared in Great Britain. Appl. Environ. Microbiol. 2011, 77, 3741-3748.

29. Matt, M.; Weyermair, K.; Pless, P. Statistical Analysis of Risk Factors for Campylobacter Colonization at the Farm Level. In Proceedings of the XVth International Congress in Animal Hygiene (ISAH) Congress, Vienna, Austria, 3-7 July 2011; pp. 765-767.

30. Ellis-Iversen, J.; Ridley, A.; Morris, V.; Sowa, A.; Harris, J.; Atterbury, R.; Sparks, N.; Allen, V. Persistent environmental reservoirs on farms as risk factors for Campylobacter in commercial poultry. Epidemiol. Infect. 2012, 140, 916-924.

31. Hald, B.; Skovgård, H.; Bang, D.D.; Pedersen, K.; Dybdahl, J.; Jespersen, J.B.; Madsen, M. Flies and Campylobacter infection of broiler flocks. Emerg. Infect. Dis. 2004, 10, 1490-1492.

32. Sommer, H.M.; Heuer, O.E.; Sørensen, A.I.V.; Madsen, M. Analysis of factors important for the occurrence of Campylobacter in Danish broiler flocks. Prev. Vet. Med. 2013, 111, 100-111.

33. Verordnung der Bundesministerin für Gesundheit, Familie und Jugend über Gesundheitskontrollen und Hygienemaßnahmen in Geflügel-Betrieben; BGB1. II Nr. 100/2007; Ministry of Health: Vienna, Austria, 2007.

34. Hald, B.; Sommer, H.M.; Skovgård, H. Use of fly screens to reduce Campylobacter spp. introduction in broiler houses. Emerg. Infect. Dis. 2007, 13, 1951-1953. 
35. Hue, O.; Le Bouquin, S.; Laisney, M.-J.; Allain, V.; Lalande, F.; Petetin, I.; Rouxel, S.; Quesne, S.; Gloaguen, P.-Y.; Picherot, M.; et al. Prevalence of and risk factors for Campylobacter spp. contamination of broiler chicken carcasses at the slaughterhouse. Food Microbiol. 2010, 27, 992-999.

36. Ridley, A.M.; Morris, V.K.; Cawthraw, S.A.; Ellis-Iversen, J.; Harris, J.A.; Kennedy, E.M.; Newell, D.G.; Allen, V.M. Longitudinal molecular epidemiological study of thermophilic Campylobacters on one conventional broiler chicken farm. Appl. Environ. Microbiol. 2011, 77, 98-107.

37. Berrang, M.E.; Northcutt, J.K.; Cason, J.A. Recovery of Campylobacter from broiler feces during extended storage of transport cages. Poult. Sci. 2004, 83, 1213-1217.

38. Ridley, A.; Morris, V.; Gittins, J.; Cawthraw, S.; Harris, J.; Edge, S.; Allen, V. Potential sources of Campylobacter infection on chicken farms: Contamination and control of broiler-harvesting equipment, vehicles and personnel: Sources of Campylobacter associated with flock thinning. J. Appl. Microbiol. 2011, 111, 233-244.

39. Xiao, N.; Huang, H.-Z.; Li, Y.; He, L.; Jin, T. Multiple failure modes analysis and weighted risk priority number evaluation in FMEA. Eng. Fail. Anal. 2011, 18, 1162-1170.

40. Habib, I.; Berkvens, D.; de Zutter, L.; Dierick, K.; Van Huffel, X.; Speybroeck, N.; Geeraerd, A.H.; Uyttendaele, M. Campylobacter contamination in broiler carcasses and correlation with slaughterhouses operational hygiene inspection. Food Microbiol. 2012, 29, 105-112.

41. Stern, N.J.; Robach, M.C. Non-destructive sampling of live broiler for Campylobacter. J. Appl. Poult. Res. 1995, 4, 182-185.

42. Microbiology of Food and Animal Feeding Stuffs-Horizontal Method for Detection and Enumeration of Campylobacter spp. Part 1: Detection Method; ISO 10272-1:2006; International Organization of Standardization: Geneva, Switzerland, 2006.

43. Pless, P.; Matt, M.; Wagner, P. Evaluation of Risk Factors Associated with Campylobacter spp. in Broiler Flocks. In Proceedings of the XVth International Congress in Animal Hygiene (ISAH) Congress, Vienna, Austria, 3-7 July 2011; pp. 185-188.

(C) 2013 by the authors; licensee MDPI, Basel, Switzerland. This article is an open access article distributed under the terms and conditions of the Creative Commons Attribution license (http://creativecommons.org/licenses/by/3.0/). 